\title{
“The Whitechapel experiment”, o projeto Éden e a busca por uma experiência afetiva total.
}

“The Whitechapel experiment”, the Éden project and the search for a total affective experience.

palavras-chave:

Hélio Oiticica;

"The Whitechapel experiment"; ambiente Éden; participação do espectador

keywords: Hélio Oiticica; "The Whitechapel experiment"; Éden installation; spectator participation
Este artigo tem por objetivo analisar a exposição "The Whitechapel experiment", de Hélio Oiticica, realizada em 1969, em Londres, discutindo a polêmica que cercou sua montagem, como se deu sua recepção na imprensa local naquele momento e como ela vem provocando novas leituras. Não tem por intenção procurar reconstituir a mostra, mas dar novos sentidos a documentos e testemunhos diversos, alguns dos quais pouco estudados, relacionando-os de modo a enfatizar a importância das experiências de Oiticica no Reino Unido para seu programa de trabalho nos anos seguintes. Ele se relaciona à pesquisa desenvolvida em estágio de pós-doutorado, no centro de pesquisa TrAIN, da University of the Arts, Londres, com bolsa Fapesp.

This article aims to analyze Hélio Oiticica's exhibition "The Whitechapel experiment", held in 1969, in London, discussing the debate that surrounded its achievement, the reception of the local press at the time, and how it has recently provoked new readings. It is not our intention to reconstitute the show, but to give new meanings to various documents and testimonies, some of which have been little studied, relating them in such a way as to emphasize the importance of Oiticica's experiences in the United Kingdom for his work in the following years. This article relates to the research I developed in 2015 as a visiting academic at TrAIN/University of the Arts, London, with a grant from Fapesp.

* Universidade Estadual de Campinas [Unicamp]. 
depois da Whitechapel (primeira e última experiência) depois de Paris com Ceres Franco, fazendo Robho de Jean Clay depois de Los Angeles com Lygia Clark, cuja comunicação reviveu e engrandeceu com o contato americano depois de New York com Gerchman, cujo trabalho cresce dia a dia estou 'again' em Londres

\section{E NÃO TENHO LUGAR NO MUNDO'}

Em 2009, por ocasião de sua reabertura após trabalhos de expansão e renovação, a galeria londrina Whitechapel publica uma coletânea intitulada A manual for the 21 st century art institution ${ }^{2}$, em que diversos autores, em doze capítulos, discutem e analisam as diferentes tipologias que compõem o espaço expositivo institucional, da recepção à livraria, do arquivo às exposições, do auditório ao setor educativo etc. Nas palavras do editor, o conjunto de textos ali reunidos examinava "os principais desenvolvimentos na prática artística e na crítica institucional ao longo do século passado”, considerando as modificações ocorridas no pensamento e na prática museal ${ }^{3}$. Muitos autores tomaram como fundamento de sua argumentação eventos e experiências que tiveram lugar na própria Whitechapel, instituição de caráter público que está em atividade desde 1901. Assim, no capítulo dedicado a "exposições", Adam Szymczyk elege duas mostras dentre as várias ali realizadas para discorrer sobre as transformações na relação entre público e obra: a primeira, dedicada a Jackson Pollock, em 1958, e a segunda, organizada por Hélio Oiticica em 1969. Sua intenção é clara: apontar a relevância e originalidade da proposta do artista brasileiro.

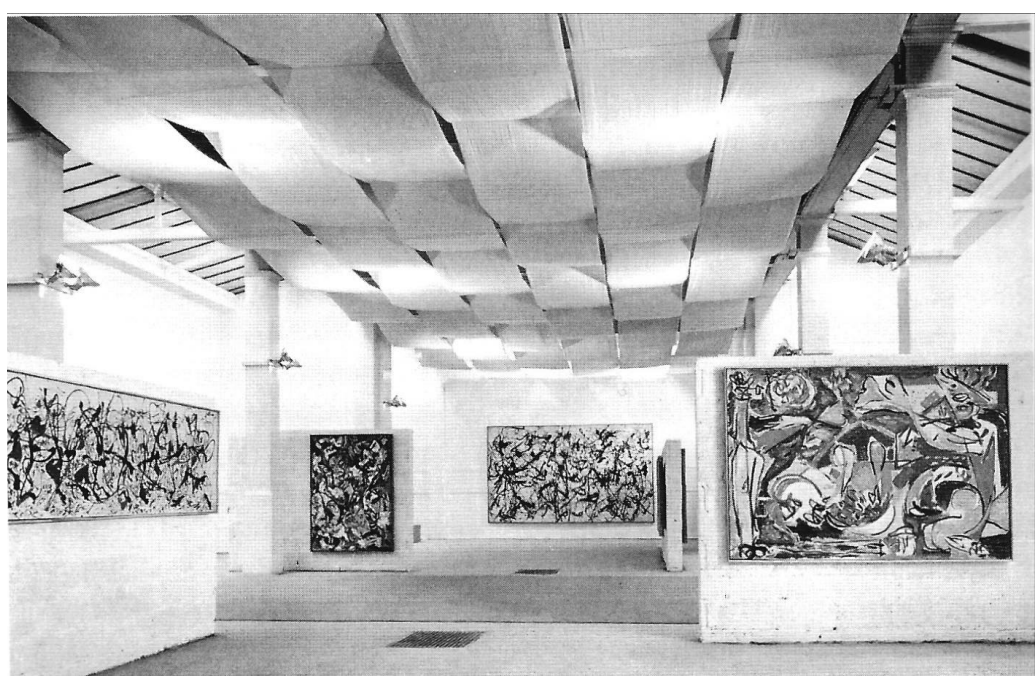

Maria de Fátima Morethy

\section{Couto}

"The Whitechapel experiment", o projeto Éden e a busca por

uma experiência afetiva total.

1. OITICICA, Hélio.

Londocumento, 27 ago. 1969

2. A coletânea tem por subtítulo "Just what is it that makes today's institutions so different, so appealing?", que alude à célebre colagem de Richard Hamilton, Just what is it that makes today's homes so different, so appealing?, criada como peça publicitária para uma das exposições mais famosas da galeria Whitechapel, "This is tomorrow", realizada em 1951.

3. SHARMACHARJA, Shamita (ed.). A manual for the 21st century art institution: just what is it that makes today's institutions so different, so appealing? Londres: Whitechapel Art Gallery; Koenig, 2009, p. 10-11.

Fig. 1

Exposição de Jackson Pollock na Whitechapel em 1958. (foto Sam Lambert) Fonte: SHARMACHARJA, Shamita (ed.). A manual for the 21st century art institution: just what is it that makes today's institutions so different, so appealing? Londres: Whitechapel Art Gallery; Koenig, 2009, p. 58. 
Em suas palavras, enquanto a mostra de Pollock, concebida pelo arquiteto Trevor Dannatt com painéis removíveis dispostos no

4. SZUMCZYK, Adam. From 'the best kind of hanging' to the 'Eden plan'. In: SHARMACHARJA, Shamita (ed.). Op. cit., p. 56-67. 0 titulo do capítulo é por si só elucidativo.

5. Ibidem, p. 59 e 63.

Fig. 2

Vista parcial da "The Whitechapel experiment", exposição. Fonte: ITAÚ CULTURAL. Programa Hélio Oiticica. São Paulo, [s/d]. formato de cruz, jogos específicos de luz, tapetes no chão e tecidos fixados ao teto, criava um espaço de isolamento no qual as obras se destacavam e os espectadores se moviam como se estivessem em uma procissão, a arquitetura concebida por Hélio Oiticica para sua exposição envolvia uma tipologia completamente diferente, com construções aparentemente improvisadas que serviam para abrigar pessoas ao invés de exibir objetos ${ }^{4}$. Szymczyk descreve em detalhes o projeto de Oiticica de ocupação integral do espaço expositivo, distinguindo-o de propostas tradicionais:

Em vez das paredes e sólidos painéis que prevaleceram na exposição de Pollock, mas que também eram usadas pela Whitechapel desde ao menos a exposição Modern Dutch Art, de 1921, Oiticica tomou partido por espaços semi-fechados com diferentes graus de transparência e negociável penetrabilidade entre as seções (...). [Criou com isso] uma narrativa circular e orgânica com múltiplas escolhas de direção. O movimento dos espectadores era conduzido pela dinâmica da alternância entre momentos individuais mais contemplativos ou mesmo meditativos e outros onde se podia imaginar situações coletivas efêmeras em desenvolvimento - visitantes falando sobre suas experiências e compartilhando várias atividades. ${ }^{5}$

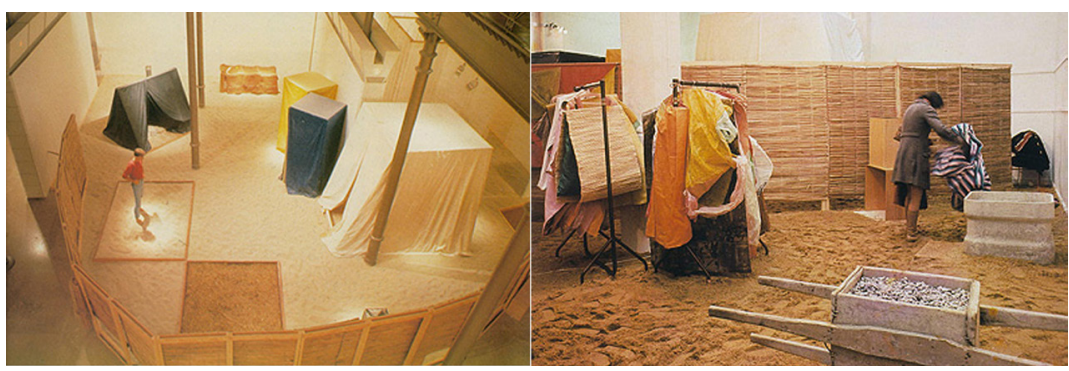

Quatro décadas após sua realização, "The Whitechapel experiment" é portanto louvada na Inglaterra por sua ousadia conceitual e por seu trato inovador com o "espectador". Evidentemente esta nova postura, que contrasta com a tíbia recepção que a mostra recebeu da crítica especializada londrina na ocasião de sua apresentação, reflete as mudanças de pensamento nos conceitos de obra de arte e de exposição, bem como acompanha o interesse crescente dos centros culturais hegemônicos por produções antes à margem das narrativas canônicas. Some-se a isso o fato de o autor do artigo, Adam Szymczyk, ser figura ativa no circuito da arte contemporânea na Europa, com 
especial interesse por propostas artísticas de caráter crítico e, por isso, plenamente capaz de compreender o vigor do trabalho de Oiticica na atualidade ${ }^{6}$.

No caso de Oiticica, seu trabalho vem se firmando no cenário internacional desde sua primeira retrospectiva itinerante pela Europa e pelos Estados Unidos, que percorreu as cidades de Roterdã, Paris, Barcelona, Lisboa e Mineápolis entre 1992 e 1994. Poucos anos mais tarde, em 1997, a Documenta 10, sob a curadoria de Catherine David, deu grande destaque à sua obra, bem como à de Lygia Clark. Em 2006 e 2007, outra grande mostra, "The body of color", apresentada no Museu de Belas Artes de Houston, Texas, e na Tate Modern de Londres, consolidou sua fama fora do Brasil. Na apresentação do catálogo desta exposição, Vicente Todolí, então diretor do museu londrino, afirma que o trabalho de Oiticica "é bastante relevante para o público internacional hoje" e declara estar "feliz em poder apresentar uma análise tão abrangente sobre Oiticica na Tate Modern - em uma cidade que acolheu uma importante exposição de seu trabalho na Whitechapel Gallery em 1969 - e, ao fazê-lo, revelar o extraordinário alcance de sua obra para um público mais amplo"7. Ademais, nessa ocasião, a Tate adquiriu um conjunto de trabalhos do artista brasileiro, entre eles Tropicália, destaque da exposição de $1969^{8}$, e montou uma pequena mostra à parte, "Oiticica in London - Tate Collection", que foi acompanhada da publicação da coletânea Oiticica in London, que reúne diversos depoimentos de pessoas que o conheceram, além de textos de pesquisadores de seu trabalho.

"The Whitechapel experiment" foi a segunda (e última) exposição individual de Oiticica em vida. Embora apresentada dentro das quatro paredes de uma galeria, ela foi pensada como um "ambiente total" (projeto Éden) e não enquanto uma sucessão de obras isoladas. Como aponta David Sperling, "mais do que retrospectiva de sua trajetória, o que pela primeira impressão a montagem de diversas de suas obras no recinto da Whitechapel Gallery deixaria supor, (...) Éden é um projeto, brotamento de brotamentos, patamar extremo das reflexões do artista naquele momento, planejamento ambiental"'.

Concebida como uma exposição-manifesto, ou como uma "experiência mostra" (como dirá o artista), ela evidenciará a rejeição de Oiticica por "formas antigas de arte" e seu crescente interesse por "experiências que se prolonguem para o campo sensorial, como uma 'experiência afetiva' total" ${ }^{10}$. Sua história, evidentemente, deve ser compreendida no contexto de uma trajetória singular, lúcida e coerente, que foi marcada por um processo contínuo de criação de
Maria de Fátima Morethy Couto

"The Whitechapel experiment", o projeto Éden e a busca por uma experiência afetiva total.

6. Szymczyk foi o curador-chefe da Kunsthalle da Basiléia de 2003 a 2014 e o diretor-artístico da "Documenta 14" (2017), que teve como tema Learning from Athens. Em diferentes entrevistas a respeito desta edição da Documenta, Szymczyk deixou claro seu interesse em apontar as desigualdades do mundo da arte e das relações geopolíticas, afirmando, por exemplo, querer questionar

“o modo de ser e pensamento suprematista, branco e masculino, nacionalista e colonialista que continua a construir e dominar a ordem mundial". Cf. MICHALSKA, Julia. All about Adam: a profile of Documenta's activist director. The Art Newspaper, Londres, 4 jun. 2017. Documenta \& münster 2017. Disponível em: <https:// goo.gl/yq8Ej1>. Acesso em: 3 jul. 2017.

7. TODOLÍ, Vicente. Foreword. In: RAMÍREZ, Mari Carmen (org.). Hélio Oiticica: the body of color. Houston: The Museum of Fine Arts, 2007, p. 13.

8. Além da Tropicália, foram então adquiridos quatro Metaesquemas, dois Bólides, um Bilateral e um Relevo espacial.

9. SPERLING, David. Corpo + arte = arquitetura: proposições de Hélio Oiticica e Lygia Clark. In: BRAGA, Paula (org.). Fios soltos: a arte de Hélio Oiticica. São Paulo: Perspectiva, 2008, p. 121-122, grifo do autor. 
"proposições abertas ao exercício imaginativo do espectador/partici-

ano 15

ก. 30

10. OITICICA, Hélio.

Whitechapel Gallery: experiência mostra, 27 jan. 1970. In: ITAÚ CULTURAL.

Programa Hélio Oiticica. São Paulo, 2002, Arquivo Hélio

Oiticica/Programa Hélio Oiticica (AHO/PHO) 0338.70.

11. Os trechos entre aspas sem indicação de autoria são de textos do próprio artista. OITICICA, Hélio. Aparecimento do supra-sensorial na arte brasileira. In: Aspiro

ao grande labirinto. Rio de Janeiro: Rocco, 1986, p. 102.

12. OITICICA, Hélio. Aparecimento do suprasensorial na arte brasileira.

In:___ Aspiro ao grande

labirinto. Rio de Janeiro: Rocco, 1986, p. 103.

13. Ibidem, p. 104-105

14. FAVARETTO, Celso. Deslocamentos: entre a arte e a vida. Ars, São Paulo, v. 9 , n. 18, 2011, p. 100.

15. A galeria iniciou suas atividades como um Centro para os Estudos Criativos

Avançados (Centre for Advanced Creative Studyl, no apartamento de Paul Keeler, no Cornwall Gardens, próximo à Cromwell Road.

Alguns meses mais tarde, ela passa a funcionar no $\mathrm{n}^{\circ} 39 \mathrm{da}$ Wigmore Street, em imóvel de propriedade de Charles Keeler (pai de Paul Keeler), fabricante de instrumentos óticos de precisão, e contava com seu apoio financeiro. Em 1966, após dois anos de atividades, talvez em função do pouco retorno comercial pador", visando "derrubar todo condicionamento para a procura da liberdade individual" ${ }^{11}$.

Em "Aparecimento do supra-sensorial na arte brasileira", texto publicado na Revista GAM de janeiro de 1967, Oiticica já declarava sua intenção de prescindir do objeto de arte ou de servir-se dele para levar o indivíduo a uma "supra-sensação, ao dilatamento de suas capacidades sensoriais habituais, para a descoberta do seu centro criativo interior, de sua espontaneidade adormecida, condicionada ao cotidiano”. Para o artista, fazia-se necessário "desalienar o indivíduo, torná-lo objetivo no seu comportamento ético-social"12. Em sua visão,

\footnotetext{
a arte já não é mais instrumento do domínio intelectual, já não poderá ser usada como algo supremo, inatingível, prazer do burguês tomador de uísque ou do intelectual especulativo: só restará da arte passada o que puder ser apreendido como emoção direta, o que conseguir mover o indivíduo do seu condicionamento opressivo, dando-lhe uma nova dimensão que encontre uma resposta no seu comportamento. ${ }^{13}$
}

Como observou Celso Favaretto, "o campo de ação de Oiticica não era apenas o sistema de arte, mas a visionária atividade coletiva que interceptava subjetividade e significação social"14.

\section{Nos bastidores de "The Whitechapel experiment"}

Oiticica parte para a Inglaterra no início de dezembro de 1968, poucos dias antes da decretação do Ato Institucional $n^{\circ} 5$ (AI-5) no Brasil, juntamente com o poeta e amigo Torquato Neto. Seu objetivo era concretizar um projeto expositivo que começara a conceber desde que recebera um convite, em 1965, para expor na galeria Signals, em Londres, no ano seguinte. Esta galeria, ativa entre os anos de 1964 e 1966, foi fundada por Paul Keeler, em conjunto com o artista filipino David Medalla, em função de interesses comuns por uma arte experimental de caráter cinético. Sua programação era diferenciada, ousada para o cenário londrino, e contou com a participação expressiva de artistas da América do Sul, especialmente do Brasil ${ }^{15}$. Como aponta Isobel Whitelegg em texto dedicado à galeria, "das nove exposições individuais mais abrangentes ali realizadas, seis foram consagradas a artistas da Venezuela e do Brasil. Nas mostras de Lygia Clark, Carlos Cruz-Diez, Alejandro Otero, Mira Schendel e Jésus Soto, a galeria ofereceu amplo espaço para experimentação e recepção crítica"16. 
Nos dizeres de Guy Brett, que foi um dos colaboradores mais ativos da Signals e, certamente, um dos grandes interlocutores dos artistas sul-americanos na Europa, a Signals acolheu, naquele período, as mostras de maior destaque desse grupo de artistas fora de seus países de origem:

Embora Paris fosse o destino natural dos artistas brasileiros nas décadas de 1950 e 1960 - o francês era a segunda língua dos intelectuais desse período -, a Signals de Londres deu aos brasileiros e a muitos outros artistas latino-americanos a possibilidade de experimentar e exibir em uma escala que ainda não tinham alcançado em Paris. As exposições de Sérgio Camargo, Lygia Clark e Mira Schendel na galeria Signals, e a exibição de Hélio Oiticica, transferida, de forma expandida para a galeria Whitechapel em 1969, após o fechamento da Signals, constituíram, na época, suas maiores mostras fora do Brasil. ${ }^{17}$

Brett conheceu Oiticica em 1965, quando veio ao Brasil para cobrir a VIII Bienal de São Paulo para o jornal The Times, juntamente com Paul Keeler ${ }^{18}$. Segundo seu depoimento, a admiração foi imediata:

O primeiro trabalho que vimos de Hélio foram os Bólides, exibidos na Bienal de São Paulo em 1965. Ambos ficamos maravilhados. Eram na verdade peças pequenas, especialmente porque logo na sala do lado estavam os minimalistas, Donald Judd, Sol LeWitt etc. Você pode imaginar o contraste. O trabalho dos americanos tinha uma presença dura, industrial, muito "direto ao assunto". As caixas e os contêineres de vidro com terra e pigmentos de Oiticica funcionavam de forma completamente diferente, concentrando energia em um núcleo de cor material e complexidade espacial. Paul imediatamente o convidou para uma exposição em Londres [na Signals]. ${ }^{19}$

O fechamento da Signals, em 1966, levou ao adiamento da mostra de Oiticica, mas não ao seu cancelamento. Algumas obras (em sua maioria Bólides) já haviam sido despachadas para Londres e ficaram sob a guarda de Brett, que se empenhou em mostrá-las para figuras de destaque do circuito londrino, entre elas Bryan Robertson, diretor da Whitechapel desde 1952. Robertson decidiu acolher o projeto e, em carta endereçada a Oiticica, comenta que, embora lamentasse o fechamento da Signals, acreditava que sua obra seria beneficiada pela atmosfera livre e independente de uma galeria de arte de cunho não comercial ${ }^{20}$.

A Whitechapel é uma galeria de arte pública que, como vimos, está em atividade desde 1901, em região de raízes operárias (East End), ocupada maciçamente naquela época por refugiados e imigrantes, e que contava com forte comunidade judaica. Construída com o intuito
116

Maria de Fátima Morethy Couto

"The Whitechapel experiment", o projeto Éden e a busca por uma experiência afetiva total.

do empreendimento, Charles Keeler retira seu apoio, o que resultou no fechamento da Signals. Segundo Brett, eram três andares de espaços para exposição e um showroom no térreo.

16. WHITELEGG, Isobel. Signals London, Signals Latin America. In: PÉREZBARREIRO, Gabriel (org.). Radical Geometry: modern art of South America from the Patrícia Phelps de Cisneros Collection. Londres: Royal Academy of Arts, 2014, p. 57.

17. BRETT, Guy. Sérgio Camargo. In:__. Brasil experimental: arte/vida: proposições e paradoxos. Rio de Janeiro: Contra Capa, 2005, p. 161-162.

18. De acordo com vários depoimentos de Brett, o escultor Sérgio Camargo, que residia em Paris, foi o primeiro a alertar-lhe, em 1964, sobre a originalidade da produção artística brasileira contemporânea. Ao visitar o Brasil, Brett estava decidido a conhecer alguns dos artistas recomendados por Camargo, entre eles Oiticica, Mira Schendel e Lygia Clark.

19. Idem. Gostava da arte que produziam e gostava deles como pessoas: assim, nos tornamos amigos: entrevista de Guy Brett a Linda Sandino. Arte \& Ensaios, Rio de Janeiro, v. 14, n० 14, 2007, p. 221. (Edição especial Correspondência transnacional). 
de levar a arte para a população local, promovendo educação para todos dos, a galeria encontra-se contígua a uma estação de metrô, ao nível da rua, sem escadas nem hall suntuoso. Ao seu lado, funcionava uma das várias bibliotecas públicas fundadas no mesmo período, com intenção semelhante, por iniciativa de John Passmore Edwards, cujo acervo foi desfeito em 2005 e seu espaço interno incorporado ao da galeria ${ }^{21}$.

Fig. 3

Fachada da Whitechapel Gallery, [s/d]. (foto David Baugh) Fonte: <https://goo.gl/ iW209G>.

20. Carta de Bryan Robertson para Oiticica, de 28 de março de 1968. In: WHITECHAPEL ART GALLERY. Whitechapel

Gallery archive. Londres, 2009, Whitechapel Art Gallery exhibition file (WAG/EXH) 2/122. Nela, Robertson se diz impressionado pela pureza, esplendor e originalidade de suas obras e convida o artista a realizar uma exposição na galeria "no ano

seguinte, em uma escala muito maior do que a que ele havia se comprometido junto a Signals". Ele sugere ainda que a exposição ocorra "na segunda metade de 1968".

Provavelmente, esta carta é uma cópia de outra carta que

Robertson enviou para Brett em

3 de abril de 1967, solicitando que ele a encaminhasse para Oiticica, já que em 12 de abril deste mesmo ano o artista escreve para Brett relatando a felicidade de todos ao saber que ele iria expor na Whitechapel.

\section{A reforma citada acima,} concluída em 2009, foi realizada com o objetivo de integrar o espaço interior da biblioteca ao da galeria.

Manteve-se, porém, a fachada da biblioteca, na qual ainda se pode ver a inscrição "The Passmore Edwards Library".

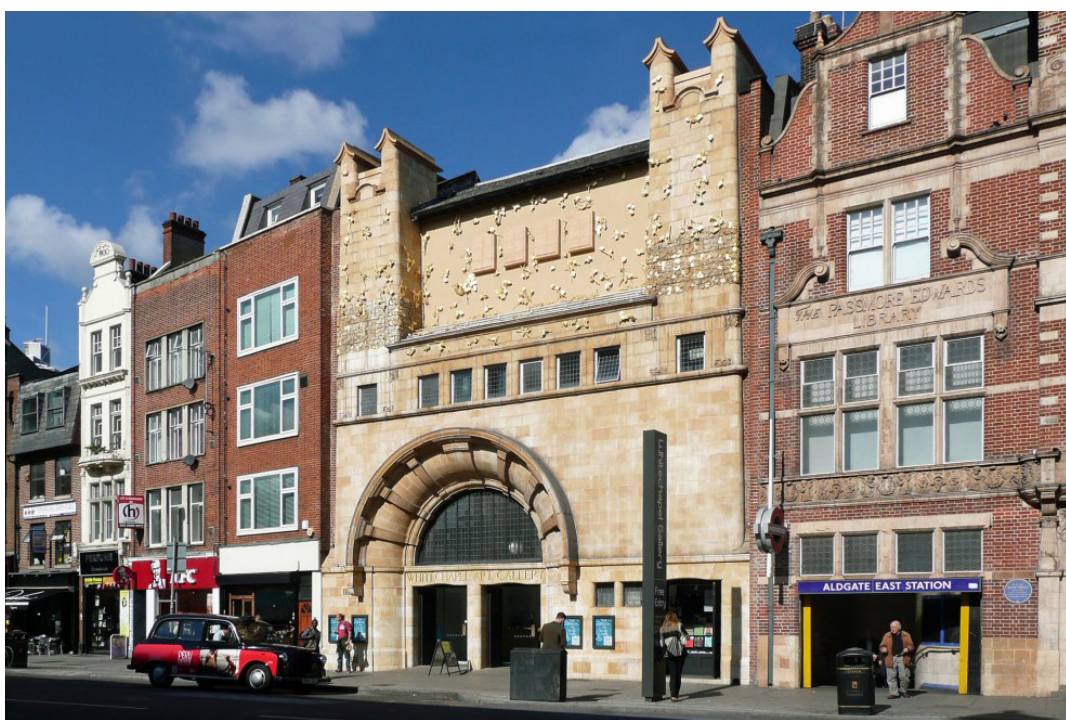

O prédio da Whitechapel, que até hoje destoa de seu entorno por sua simplicidade e refinamento, foi projetado pelo arquiteto Charles Harrison Townsend no final do século XIX, dentro do estilo art nouveau. Catherine Lampert dirigiu a galeria entre 1988 e 2002 e assim se refere à sua história:

É certo que até os anos 1960 a Whitechapel tinha menos competição no campo da arte moderna. Exposições ocasionais ocorriam em galerias, para locação ou de gestão privada, como a Burlington, Lefevre ou Grosvenor; mais tarde, houve as mostras patrocinadas pelo Arts Council e realizadas na Tate ou ainda algumas poucas exposições de inverno da Royal Academy, que eram ansiosamente aguardadas. Em 1901 tínhamos vantagens estruturais por exemplo, a galeria foi construída para ter luz elétrica, em época na qual os museus nacionais ainda fechavam suas portas ao escurecer. $\mathrm{O}$ que algumas pessoas, tanto agora como antes, talvez considerem desvantagens - um público que abrange diferentes classes sociais, com uma alta proporção de imigrantes, e uma localização em um bairro desigual, parcialmente 
industrial, onde os artistas gravitam, tornaram-se elementos indissolúveis da tradição não conformista da galeria. ${ }^{22}$

Se a última afirmação (sobre a tradição não conformista da galeria) talvez devesse ser nuançada, uma vez que a agenda de exposições da Whitechapel foi bastante diversificada e irregular em termos de foco de interesse, fato é que a longa gestão de Bryan Robertson (1952-1968) foi majoritariamente devotada à causa da arte moderna e contemporânea e alavancou a reputação da galeria enquanto espaço experimental. Algumas mostras realizadas sob sua direção movimentaram a cena local, entre elas a célebre "This is tomorrow", em 1956, as retrospectivas de vários artistas norte-americanos (Jackson Pollock em 1958, mencionada acima, Mark Rothko em 1961, Robert Rauschenberg em 1964) e ingleses (Barbara Hepworth, em 1954 e 1962, Henry Moore, em 1960, Anthony Caro, em 1963), e outras devotadas a jovens artistas, como as quatro edições de "The new generation" (1964-1968).

Em função de seus interesses e afinidades, Robertson, portanto, não teve dificuldades em reconhecer o potencial do trabalho de Oiticica, mas talvez esperasse realizar uma exposição menos ambiciosa, sobretudo por se tratar de um artista desconhecido no meio internacional. Conforme discutiremos adiante, ele chegou a duvidar de sua viabilidade, por conta dos planos audaciosos de ocupação de todo o espaço da galeria. Ressalte-se, porém, que intervenções ousadas no espaço expositivo não eram novidade na Whitechapel. Em "This is tomorrow", por exemplo, o espaço da galeria foi dividido entre doze grupos de artistas, escultores, arquitetos e designers, que tiveram total liberdade para abordar o tema da mostra por meio de trabalhos coletivos diversos.

Já Oiticica, por sua vez, mostrava-se entusiasmado pela possibilidade de realização de uma mostra de maior envergadura e impacto, e rapidamente passou a idealizá-la de modo integrado e com um ambiente específico de grandes dimensões (projeto Éden). Em 12 de abril de 1967, ele escreve para Brett e declara estar seguro de que a exposição será um grande evento em Londres ${ }^{23}$. Em outubro do mesmo ano, em nova carta a Brett, menciona o projeto Éden - "um campus experimental, uma espécie de taba, onde todas as experiências humanas são permitidas (...) uma espécie de lugar mítico para as sensações, para as ações, para a feitura de coisas e construção do cosmos interior de cada um" ${ }^{24}$-, e declara:

Guy, nunca estive tão contente quanto com este plano do Éden. Sinto-me completamente livre de tudo, até de mim mesmo. Isso me veio com as novas
Maria de Fátima Morethy Couto

"The Whitechapel experiment", o projeto Éden e a busca por

uma experiência afetiva total.

22. LAMPERT, Catherine. Finding our territory. In: LAMPERT, Catherine; BRETT, Guy; LIVINGSTONE, Marco et al. The Whitechapel Art Gallery centenary review. Londres: Whitechapel Art Gallery, 2001, p. 7.

23. Carta de Oiticica para Guy Brett, de 12 de abril de 1967. In: WHITECHAPEL ART GALLERY. Whitechapel Gallery archive. Londres, 2009, WAG/EXH 2/122. Entre os anos de 1967 e 1969 , Oiticica escreveu longas cartas para Brett sobre seus planos para a exposição.

24. Carta de Oiticica para Guy Brett, de 27 de outubro de 1967. In: WHITECHAPEL ART GALLERY. Whitechapel Gallery archive. Londres, 2009, WAG/EXH 2/122.

Tradução minha.Etrordiu 
ARS

ano 15

n. 30
25. Ibidem. Tradução minha.

26. Carta de Oiticica para Guy Brett, de 27 de outubro de 1967. In: WHITECHAPEL ART GALLERY. Whitechapel

Gallery archive. Londres, 2009, WAG/EXH 2/122.

Tradução minha., grifo do artista.

27. Como discutiremos a seguir, Oiticica montara um ambiente semelhante, menor, em 1966.

28. Em "A participação jogo", texto de 4 de setembro de 1966, Oiticica escreve que “com a experiência do jogo de sinuca armado por mim no MAM do Rio dentro da exposição "Opinião 66", inaugurada a 25 de agosto, descobri, definitivamente, o sentido do jogo como participação, ou seja a proposta livre do jogo em vez de estrutura-obra para que sejam participadas. Aqui o jogo, tal como é, é a obra; nem mais, nem menos.

(...) A construção do jogo é também uma forma patente de antiarte, que não se resumiria apenas nas apropriações, ou no sentido delas, mas também numa construção do jogo indicando outra possibilidade da "obra antiarte"'. OITICICA, Hélio. A participação no jogo, 4 set. 1966. In: ITAÚ CULTURAL.

Programa Hélio Oiticica.

São Paulo, 2002, AHO/PHO

0251.66 . ideias a que cheguei sobre o conceito de Supra-Sensorial; para mim toda a arte resume-se a isso: a necessidade de um significado suprassensorial de vida, em transformar os processos de arte em sensações de vida. ${ }^{25}$

Em fevereiro de 1968, Oiticica retoma o assunto da exposição, cuja data ainda não havia sido definida, e declara que tem que ir para Londres, do contrário não conseguirá construir "esta imagem de um estado de coisas em sua totalidade" ${ }^{26}$. Sua intenção de criar um novo ambiente com alguns de seus Núcleos, Penetráveis (entre eles Tropicália, montada pela primeira vez em 1967 na exposição "Nova objetividade brasileira"), Bólides e Parangolés, que remetesse a experiências da vida cotidiana, mas que possibilitasse ao participador elaborar, de modo livre, sensações que lhe eram despertadas pela experiência vivenciada no espaço, fazia-se cada vez mais forte ${ }^{27}$. Além de obras já conhecidas, Oiticica prepara para a mostra seus primeiros Ninhos, "células" para serem habitadas pelo participador, numa vivência introspectiva, propícia para a participação criativa e prazerosa, que ele definirá em seguida como Crelazer (neologismo que congrega as noções de criação e lazer). A exposição contaria ainda com uma sala de sinuca, nos moldes da que ele apresentara na mostra "Opinião 66", no Brasil (Mesa de bilhar apropriação d'après $\mathrm{O}$ café noturno de Van Gogh), e com a qual, segundo suas palavras, descobrira a "participação livre no prazer"28.

Poucos meses mais tarde, em julho, Oiticica envia um plano detalhado, com desenhos precisos, minuciosos, de todo o projeto expográfico para Bryan Robertson (que incluía até mesmo um pequeno armário para colocar os sapatos dos espectadores que quisessem entrar no ambiente Éden), desenhos estes que ele e Rogério Duarte haviam realizado exaustivamente em junho e julho, conforme ele relata a Lygia Clark, em carta na qual menciona os vários contratempos que enfrentou em relação à mostra:

Hoje resolvi escrever pois estou livre: deitado e lendo, depois de embalar semana passada 18 caixotões e 22 volumes para Londres, para uma exposição que é eternamente adiada e creio que nem vai sair - em todo caso as coisas vão e eu também: se não arranjar com o Itamaraty a passagem vou de cargueiro (100 dólares só!) sem um tostão. Mário estará lá em novembro (minha exposição ia ser em novembro, mas o Bryan Robertson ficou meio chocado com o ambiente que mandei planejado) (...) O grande mal foi eu ter sempre lidado com o Bryan (o dono da galeria) através de Guy Brett, logo o que aconteceu foi o seguinte: ele se sente sempre obrigado a dar satisfações ao Guy e nunca a mim, deixando tudo vago - Guy Brett está furioso com 
os adiamentos. Os planos ficaram geniais: a galeria era enorme e eu não acredito mais na "obra figurada", por isso incorporei tudo num planejamento ambiental, inclusive coisas que seriam construídas lá. Não modificarei um centímetro do planejado - ou tudo ou nada. (...) De obras que figuram lá está cheio. $\mathrm{O}$ que será que o cara quer mais? Creio que ele não entendeu bem as coisas e vou escrever-lhe energicamente sem agressão mas botando os pontos nos ii; Mário [Pedrosa] vai dar explicações também quando chegar lá. A verdade é que pra mim foi bom ele ter ficado espantado; pois se ficam aqui não é milagre, mas lá, numa galeria "pra frente" na cidade mais "pra frente" do mundo é uma honra. Creio que a crise é aqui e lá também. ${ }^{29}$

De fato, Oiticica escreve em seguida para Robertson com o intuito de marcar sua posição. Não se tratava, para ele, de colocar o projeto em questão, mas de reafirmar sua pertinência. Às reticências expressas por Robertson, em telegrama enviado ao artista, sobre o projeto expositivo e em especial sobre o Éden, Oiticica responde afirmando que poderá reconsiderar alguns aspectos da mostra, mas não modificá-la por completo de modo a transformá-la em uma exposição convencional de obras não convencionais. Além disso, ele informa que várias obras já haviam sido despachadas para Londres, com o apoio do Itamaraty, e que ele próprio viajará em dezembro, quando terão a oportunidade de conversar pessoalmente:

Infelizmente, não consegui segurar as obras aqui por mais tempo: o Itamaraty tinha um compromisso oficial comigo de enviá-las em outubro de 68 e seria desastroso mais delongas. (...) Eu não consigo ver a razão para algumas de suas dúvidas, embora eu esperasse por elas. (...) Tenho certeza de que você não tem uma visão completa do meu trabalho: como você pode ver pela lista que estou lhe enviando (...) há um grande número de "destaques", de obras que podem ser consideradas peças individuais. O ambiente é muito importante, pois é a introdução-informativa-sensorial [informative-feeling-introductory] de toda a exposição. (...) É claro que poderemos fazer reconsiderações sobre a forma desse ambiente, sobre seus elementos, ou sobre as obras que seriam feitas em Londres, mas nunca sobre seu sentido: tenho certeza de que todas as qualificações exigidas para uma exposição de arte foram preenchidas, até em um grau muito elevado. ${ }^{30}$

Conforme mencionado acima, Oiticica parte para Londres em dezembro de 1968 e a exposição é finalmente realizada, do modo por ele concebido, entre fevereiro e abril de 1969. O próprio artista reconhecerá em seguida que "a total liberdade dada pela diretoria da galeria" foi
Maria de Fátima Morethy Couto

"The Whitechapel experiment", o projeto Éden e a busca por uma experiência afetiva total.

29. Carta de Hélio Oiticica para Lygia Clark, de 15 de outubro de 1968. In: FIGUEIREDO, Luciano (org.). Lygia Clark Hélio Oiticica: Cartas 1964-74. Rio de Janeiro: Editora da UFRJ, 1996, p. 145.

30. Carta de Oiticica para Bryan Robertson, de 28 de outubro de 1968. In: WHITECHAPEL ART GALLERY. Whitechapel Gallery archive. Londres, 2009, WAG/EXH 2/122. Tradução minha. 

Oiticica, Robertson retira-se da direção da Whitechapel, sendo substitu-

31. OITICICA, Hélio.

Experiência londrina: subterrânea, 27 jan. 1970. In: ITAÚ CULTURAL. Programa Hélio Oiticica. São Paulo, 2002, AHO/PHO 0290/70, p. 2.

32. Lygia Clark escreve preocupada para Oiticica em novembro, avisando-lhe dos rumores sobre a saída de Robertson, mas aconselha-o a embarcar de qualquer modo. Carta de Lygia Clark para Hélio Oiticica, de 14 de novembro de 1968. In: FIGUEIREDO, Luciano (org.). Op. cit., p. 80.

33. Em entrevista concedida para o Pasquim em agosto de 1970, Oiticica não menciona o auxílio concedido pelo Itamaraty e afirma ter "passado um ano em Londres nas condições mais precárias. Cheguei em Londres com dez dólares no bolso e fiquei um ano, não me pergunte como, porque é um mistério". Cf. OITICICA, Hélio. Entrevista para o Pasquim Icom Capinam). In: OITICICA FILHO, César; COHN, Sergio; VIEIRA, Ingrid (orgs.). Hélio Oiticica. Rio de Janeiro: Azougue, 2009, p. 77-78. (Série Encontros).

34. MARK, Glazebrook: director of the Whitechapel Art Gallery, 1969-72. In: BRETT, Guy; FIGUEIREDO, Luciano (orgs.). Oiticica in London. Londres: Tate Gallery, 2007, p. 40-41. (Depoimento). ído por Mark Glazebrook ${ }^{32}$. Segundo Guy Brett, que acompanhava tudo de perto e se mostrava preocupado com as constantes indecisões sobre a mostra, a relação de Robertson com os administradores da Whitechapel chegara a uma crise, em função de uma atuação por demais independente.

Glazebrook entra em cena tardiamente e não interfere na agenda previamente estabelecida. Faz-se necessário assinalar, porém, que ele imediatamente retoma o contato iniciado com a Embaixada brasileira em Londres por seu antecessor, com vistas a obter apoio financeiro para a realização da mostra, e não hesita em escrever que a galeria contava com pouquíssimos recursos em caixa e talvez tivesse que fazer cortes em sua programação caso não conseguisse ajuda. Contudo, também na Embaixada brasileira houve uma troca de agentes nesse mesmo período: Vera Pacheco Jordão é substituída no posto de adido cultural pelo escritor Antonio Olinto, que se mostra solícito, mas afirma só ter autorização para disponibilizar $£ 200$ para o evento, quando o pedido inicial de Glazebrook remontava a $£$ 600. Em 5 de março de 1969, Glazebrook envia nova carta para Olinto, com orçamento detalhado dos gastos da exposição, que totalizaram $£ 1.114,00$, entre compra e aluguel de materiais para a realização do projeto e gastos extras com segurança. Ao que tudo indica, a negociação não avançou muito, pois em 29 de abril Glazebrook volta a escrever para Antonio Olinto, cobrando as £200 anteriormente prometidas. Registre-se porém que a Embaixada e o Itamaraty arcaram com todos os custos de transporte das obras, além de terem disponibilizado US\$ 410 para que Oiticica pudesse viajar para Londres. Cabe também mencionar que o Embaixador do Brasil em Londres, Sérgio Corrêa Affonso da Costa, e Antonio Olinto compareceram à inauguração da exposição.

Apesar de todos os percalços, a relação de Oiticica com Glazebrook parece ter sido das mais amistosas, chegando este a acolher o artista em sua casa ao perceber sua penúria ${ }^{33}$. "Ele veio para ficar alguns dias e permaneceu por pelo menos três meses", afirma Glazebrook em depoimento tardio. "Eu gostei muito da mostra. Era vital e diferente. E gostava e admirava Hélio enquanto pessoa. Por outro lado, confesso que falhei em prever o quanto ele se tornaria importante. Embora carismático, ele era completamente desprovido de arrogância”34.

\section{A exposição em cartaz}

Na opinião de Guy Brett, que preparou o catálogo e escreveu o texto de apresentação da mostra, 
Experimento Whitechapel ou Experiência Whitechapel (ele [Oiticica] não usava a palavra exposição) foi um dos mais audaciosos eventos de artes visuais dos anos 1960 e 1970 em Londres. (...) Mais que uma simples e mecânica forma de behaviorismo, o Éden de Oiticica se revelava um convite para a brincadeira e o devaneio, cujos fins eram abertos e incondicionais. Havia Bólides para serem explorados com as mãos ou pelo olfato; cabines para devaneios solitários e outros espaços mais comunais; Parangolés para vestir e dançar; e Ninhos, um grupo de caixas com cerca de dois metros por um, divididas por véus, em que o visitante era convidado a torná-los habitáveis a seu próprio modo e com materiais de sua escolha. (...) Durante anos, a exposição de Oiticica foi lembrada no mundo da arte britânica. A mostra inspirou profundamente inúmeros artistas e outros que tiveram contato com ela, tendo permanecido alojado em suas mentes como uma influência libertadora. ${ }^{35}$

Sobre a recepção da crítica local à exposição, Brett assinala, contudo, que ela foi dividida:

Paul Overy escreveu uma crítica favorável em The Listener, assim como Elizabeth Glazebrook em Queen. Jasia Riechardt, da Architectural Design, levou a obra a sério, mas não a ponto de tirar os sapatos para entrar em Éden. The Observer descartou a mostra como algo infantil, e para o Sunday Telegraph ela era menos interessante que "uma rampa de esqui seca". Os dois últimos críticos viram a obra de forma meramente literal e ficaram decepcionados por seu fracasso em equiparar-se ao "mundo real".36

Como assinalado anteriormente, Brett desempenhou relevante papel na difusão do trabalho dos artistas sul-americanos no Reino Unido dos anos 1960, atuando como um interlocutor qualificado, como um crítico receptivo e militante. Em sua longa carreira como crítico e curador, demonstra especial interesse pela produção brasileira moderna e contemporânea. Gostaria aqui de enfatizar que ele reconheceu de primeira hora a originalidade das propostas de Oiticica e de Lygia Clark, em especial no que dizia respeito à participação do espectador. Em livro publicado em 1968, Kinetic art: the language of movement, Brett ressaltou o ineditismo de suas proposições, considerando-as "uma contribuição especificamente brasileira para a arte, uma espécie de cineticismo do corpo", que vai "direto ao cerne da atividade do espectador em diálogo com o trabalho" e que se tornava tecnicamente mais primitiva - e mais fundamental - à medida que evoluía ${ }^{37}$. Apontava, assim, as diferenças existentes entre as propostas dos dois artistas brasileiros e as experiências contemporâneas de vários outros artistas no campo da
Maria de Fátima Morethy Couto

"The Whitechapel experiment", o projeto Éden e a busca por uma experiência afetiva total.

35. BRETT, Guy. Experimento Whitechapel II. In: Op. cit., p. 42.

36. Ibidem, p. 47.

37. Idem. Kinetic art: the language of movement. Londres: Studio Vista, 1968, p. 65. 
arte cinética, mais afeitas à exploração do movimento mecânico e dos efeitos óticos. Anos mais tarde, Brett dirá ter adorado o ambiente Éden,

38. BRETT, GUY. Gostava

da arte que produziam e gostava deles como pessoas. Assim, nos tornamos amigos. Entrevista de Guy Brett a Linda Sandino. Arte \& Ensaios,

Rio de Janeiro, v. 14, n' 14 , 2007, p. 227-229. (Edição especial Correspondência transnacional).

39. PASQUALINI, Marco. A Whitechapel Art Gallery e a internacionalização da arte brasileira: duas exposições. In: COLÓQUIO DO COMITÊ BRASILEIRO DE HISTÓRIA DA ARTE, 33, 2013, Rio de Janeiro. Anais... Rio de Janeiro: UFRJ, 2013. p. 209-225. Disponível em: <http://bit.ly/2x64SNe>.

Acesso em 5 abril 2017.

40. DUNLOP, Ian. You can even paddle at this show. Evening

Standard, Londres, 3 mar. 1969. Tradução minha.

41. HOW to be a rebel. Daily

Mirror, Londres, $24 \mathrm{fev}$. 1969. The Inside Page, p. 15. Tradução minha. e por razões bastante consistentes: "Era como um campus, um assentamento, mas abstraído, generalizado, de modo a significar que nossa reação não era condicionada. Era como uma destilação de sensação e pensamento, mas livre de qualquer ego ou de imagens definidas. Cada um podia fazer dele o que quisesse. Sim, e eu fiz meu próprio ninho ali”38. Mas certamente não esperava uma reação completamente favorável à exposição.

Ainda a respeito da recepção da obra de Oiticica em Londres no final dos anos 1960, Marco Pasqualini aponta que

o próprio suposto sucesso da mostra é contraditório. O contexto artístico alternativo de Londres apoiou e interagiu com as obras, enquanto um público mais tradicional (senão conservador) percebeu-as como um tipo de "parque de diversões" tropical no inverno londrino. (...) Muitas revisões nos jornais falam negativamente, considerando a proposta de Oiticica fraca, sem fundamento, e sem a capacidade de reflexão que é colocada na teoria de seus textos. ${ }^{39}$

De fato, ao analisarmos os artigos de jornal dedicados à mostra que se encontram nos arquivos da Whitechapel Art Gallery (dezoito ao todo, contando-se uma entrevista de Brett com o artista, publicada na revista Studio International, e um texto de Oiticica sobre o conceito de Crelazer, publicado na Art $\&$ Artists), faz-se evidente que a recepção na imprensa escrita foi bastante mitigada, reticente. A maioria dos artigos compara - de modo negativo - a exposição de Oiticica a outras em curso na época, em Londres (Alexander Calder, Anthony Caro, Jann Haworth e Derek Jarman) ou mesmo em Bruxelas (Soto), e tece críticas aos objetivos ambiciosos do artista, tais como:

Em minha visão, os ambientes de Oiticica são em teoria duvidosos. Eu não acredito que este seja o caminho para fazer uma ponte entre arte e vida - e, na prática, eles são apenas parcialmente bem sucedidos. Por exemplo, eles se saem mal se comparados a alguns shows de menor importância em um parque de diversões. ${ }^{40}$

Interessante. Novidade. Mas dificilmente o material do qual são feitas representa uma revolução política ou estética. ${ }^{41}$

Talvez trate-se apenas um triste caso de uma sensibilidade brasileira em fricção com a literalidade anglo-saxã, mas temo Senhor Oiticica, que, não importa o dia, eu trocaria seus jogos pelo ambiente "não planejado" de uma 
praia real, uma cama de verdade, árvores reais. (...) Eu nunca imaginei que acharia conveniente atestar, na imprensa, que amo andar descalço em uma praia, chapinhar na água, ou que gosto da maioria dos outros prazeres sensuais que a vida nos oferece, sem precisar participar de uma insossa escola de esqui para os sentidos na Whitechapel. ${ }^{42}$

O que está acontecendo na Galeria Whitechapel (sob a nova direção de Mark Glazebrook, que tem uma tradição formidável a manter) não é uma exposição de arte. Não é exatamente um parque de diversões; as atrações são muito poucas e muito fracas. Certamente não é um happening: em comparação com a rua do lado de fora, oferece um refúgio de "não eventos". Parece mais uma bolha flutuando acima das emanações de Londres E1. ${ }^{43}$

Durante minha visita, muitas pessoas pareciam estar se divertindo no ambiente criado por Oiticica. A mim, pareceu-me uma moderna e sofisticada creche, que incentivava o gozo de várias sensações táteis ou de outra ordem, para participantes adultos; ainda assim, não parecia ter grande valor. ${ }^{44}$

Em um dos artigos que Oiticica, em carta a Lygia Clark, considera como favorável, o autor Charles Spencer compara seu trabalho ao de Caro, para ressaltar seu caráter de impermanência e relacioná-lo "a um entendimento humano, básico e primitivo, da instabilidade da vida e de nossas necessidades e experiência”. Ao final do texto, porém, Spencer comenta em tom irônico:

Devo, no entanto, destacar o poder do conceito ocidental de artista, mesmo para Oiticica: quando visitei Whitechapel durante sua "transformação em um pedacinho de Londres para sempre Brasil”, pedi um cartaz (em grande parte para obter informações). Ele insistiu em assiná-lo, transformando assim o pedaço de papel em um objeto desejável. Foi um pouco enervante. ${ }^{45}$

Não se trata aqui de apontar os erros e acertos na apreciação do trabalho de Oiticica pelos críticos de então, que certamente não representam a totalidade do público (especializado ou não) que frequentou a galeria, nem de questionar a validade e importância da mostra que, como vimos, vem sendo rediscutida - e valorizada - a partir de outros parâmetros. Julguei porém relevante retomar um pouco da polêmica levantada pela exposição, já que o renome alcançado pelo trabalho de Oiticica desde então parece obliterar as críticas por ele recebidas. Ademais, como observa Amanda Ruggiero, a imprensa brasileira "desde antes da exposição até a sua realização, teceu somente elogios e comentários
Maria de Fátima Morethy Couto

"The Whitechapel experiment", o projeto Éden e a busca por uma experiência afetiva total.

42. MULLINS, Edwin. This other - and unnecessary eden. Sunday Telegraph, Londres, 4 mar. 1969.

Tradução minha.

43. GOSLING, Nigel. Lotus-land, East London. The Observer, Londres, 9 mar. 1969, p. 28. Tradução minha.

44. VAIZEY, Marina. [s/título]. Arts Review, Londres, 15 mar. 1969. Tradução minha.

45. SPENCER, Charles. Private view: Caro and Oiticica, object and environment. Art \& Artists, Londres, abr. 1969, p. 4. Tradução minha. 
positivos sobre Hélio Oiticica e sobre a repercussão da imprensa inter-

46. RUGGIERO, Amanda.

Elos e assimetrias na recepção de Hélio Oiticica. 2014. Tese (Doutorado em Arquitetura e Urbanismol

- Faculdade de Arquitetura e Urbanismo, Universidade de São Paulo, São Paulo, 2014, p. 45. A autora também comenta alguns dos artigos publicados a respeito da exposição na Whitechapel na imprensa londrina.

47. Carta de Hélio Oiticica a Augusto de Campos, de 16 de outubro de 1971. Cf. BRAGA, Paula (org.). Op. cit., p. 327.

48. Carta de Oiticica a Lygia Pape, de 3 março de 1969. In: BRETT, Guy; FIGUEIREDO, Luciano (orgs.). Op. cit., p. 42. 0 trecho acima é uma tradução livre da versão em inglês, que foi reproduzida na publicação citada.

49. David Medalla participava do grupo Exploding Galaxy, que atuava mais como uma comunidade de artistas que compartilhava ideais e interesses genéricos e promovia manifestações de cultura alternativa. Na época da exposição na Whitechapel, Medalla e outros integrantes do grupo não se encontravam no Reino Unido, mas Oiticica foi recebido e acolhido pelos que ali estavam. Edward Pope, um dos integrantes do Exploding Galaxy, relembra um jantar que organizaram para o artista brasileiro e suas constantes visitas à exposição, em especial o tempo em que ele (Pope) passou lendo textos em um dos Ninhos. A respeito nacional", o que tampouco confere com o ocorrido ${ }^{46}$.

Se esse tipo de reação, hesitante e desconfiada, dos críticos londrinos talvez tenha levado Oiticica a afirmar, anos mais tarde, quando residia em Nova Iorque, que "americano é mesmo mais inteligente e mais por dentro das nossas coisas; impossível querer comparar com a Inglaterra" ${ }^{\prime 4}$, em 1969 ele se mostrou bastante satisfeito com os resultados conquistados, não apenas em termos da montagem da exposição, mas também da divulgação e repercussão de suas ideias em um meio que ele próprio considerava então mais informado do que o do Brasil. Ressalte-se que a British Broadcasting Corporation (BBC) realizou um pequeno documentário sobre a mostra, que foi exibido no programa Late Night Line-up, da BBC 2. Além disso, faz-se necessário destacar a publicação da entrevista concedida por Oiticica a Brett na revista Studio International de março de 1969, de grande circulação e credibilidade no meio artístico, e o texto de autoria do artista "On the discovery of creleisure", na Art E Artists, de abril do mesmo ano. Em carta a Lygia Pape, Oiticica declara:

Este é o meu primeiro dia de folga, já que a galeria está fechada. Foram três semanas de intensa loucura, especialmente depois da abertura, há uma semana atrás. Estar com as pessoas tem sido ainda mais desgastante do que a montagem do mostra. Insanidade total. Mas eu nunca sonhei que algumas de minhas ideias seriam tão bem recebidas, nem que acabariam tão bem. Todo mundo aqui tem mais informação, ou seja, maior experiência das coisas, e apesar do fato de não terem conhecimento de nada a nível teórico, eles têm sensações mais diretas do que eu poderia imaginar. A BBC mostrou um filme de 20 minutos da abertura, mais longo do que o da visita de Nixon a Londres, que o precedeu. Como resultado, as pessoas vêm de longe só para sentir as coisas, vestir os parangolés, tirar os sapatos no Éden etc. com inesperada paixão e interesse. ${ }^{48}$

Em entrevista concedida no Brasil em janeiro de 1970, o tom entusiasta em relação à exposição da Whitechapel persiste. Ao ser perguntado se em Londres tudo correra bem, Oiticica responde:

Bem demais. Logo que cheguei fui visitar o grupo da Exploding Galaxy que fazia lindas experiências de arte nas ruas. (...) Montar minha exposição também foi uma experiência galáxica ${ }^{49}$. Vinte artistas trabalharam comigo. Foi preciso colocar lá 27 toneladas de areia, uma célula cheia d'água, armar os ninhos-lazer onde as pessoas ficavam sentadas pensando ou simplesmente 
convivendo. Foi uma experiência bacana ver homens de negócio entrarem no recinto e obedecer a sugestão de tirar os sapatos para poder sentir as sensações táteis que o meu trabalho queria transmitir. Aqui no Museu ninguém tira o sapato, acho que o brasileiro custa tanto a ter um sapato que o ato de tirá-lo é assim como o de abandonar um "status". 50

\section{Londres, Éden e o Crelazer}

Como vimos, "The Whitechapel experiment" foi a segunda exposição individual concebida por Oiticica. A primeira, intitulada Manifestação ambiental I, foi a única exposição individual que Oiticica realizou no Brasil, a qual ocorreu em junho de 1966 na Galeria G4, Rio de Janeiro. Deve-se ressaltar que ela já foi pensada como um ambiente integrado, composto por Núcleos e Bólides, talvez como um prelúdio à mostra de Londres, uma vez que o convite de Paul Keeler para que Oiticica expusesse na Signals já havia sido feito.

Em sua coluna no Correio da Manhã, Mário Pedrosa escreve sobre Manifestação ambiental I, tomando-a como um claro exemplo de que se iniciara um "novo ciclo de vocação antiarte, não mais puramente artístico, mas cultural", que ele chama pioneiramente de "arte pós-moderna". Neste novo ciclo, "os valores propriamente plásticos tendem a ser absorvidos na plasticidade das estruturas perceptivas e situacionais", tal qual ele percebe ocorrer na proposta de Oiticica. Comparando-a à experiência dos Bichos de Clark, Pedrosa assinala "que o espectador deixava de ser contemplador passivo para ser atraído a uma ação que não estava na área de suas cogitações convencionais cotidianas, mas na área das cogitações do artista, e destas participava, numa comunicação direta, pelo gesto e pela ação" ${ }^{51}$ e conclui:

Arte ambiental é como Oiticica chamou sua arte. Não é com efeito outra coisa. Nela nada é isolado. Não há uma obra que se aprecie em si mesma, como um quadro. O conjunto perceptivo domina. (...) A ambiência é de saturação virtual, sensória. $\mathrm{O}$ artista se vê agora, pela primeira vez, em face de outra realidade, o mundo da consciência, dos estados de alma, o mundo dos valores. Tudo tem de ser agora enquadrado num comportamento significativo. (...) O inconformismo estético, pecado luciferiano, e o inconformismo psíquico social, pecado individual, se fundem..$^{52}$

Como sabemos, a obra de Oiticica já era comentada e discutida no Brasil desde fins dos anos 1950. O artista não assinara o "Manifesto
Maria de Fátima Morethy Couto

"The Whitechapel experiment", o projeto Éden e a busca por uma experiência afetiva total.

da recepção da mostra em Londres, Pope declara: “Em geral, os ninhos não eram muito habitados - houve uma lacuna, você sabe, entre o que poderia acontecer em um dos ambientes do Hélio e o que de fato aconteceu. Você pode levar um inglês à água, mas não pode forçá-lo a beber". POPE, Edward. Recollection. In: BRETT, Guy; FIGUEIREDO, Luciano (orgs.). Op. cit., p. 48. Tradução minha.

50. REGO, Norma. Mangueira e Londres na rota, Hélio propõe uma arte afetiva. In: OITICICA FILHO, César; COHN, Sergio; VIEIRA, Ingrid (orgs.). Op. cit., p. 100. Artigo publicado originalmente no jornal Última Hora, em 31 de janeiro de 1970.

51. PEDROSA, Mário. Arte ambiental, arte pós-moderna, Hélio Oiticica. In: ARANTES, Otília (org.). Acadêmicos e modernos: textos escolhidos 3. São Paulo: Edusp, 1998 , p. 355-357.

52. Ibidem, p. 357 e 360. 
ARS Neoconcreto", mas participara com intensidade dos debates subse-

ano 15

ก. 30

53. FREIRE, Cristina. Arte conceitual. Rio de Janeiro: Jorge Zahar, 2006, p. 20.

54. OITICICA, Hélio. Crelazer. In:_. Op. cit., p. 114.

55. FAVARETTO, Celso. A invenção de Hélio Oiticica. São Paulo: Edusp, 1992, p. 186.

56. Carta de Oiticica para

Pedrosa, de 15 de julho de 1969. In: FIGUEIREDO, Luciano (org.). Op. cit., p. 46.

57. Penso aqui nas proposições do grupo GRAV (Groupe de Recherche D'Art Visuel), formado em 1960 por Horacio Garcia, Julio Le Parc, François Morellet, Francisco Sobrinho, Joël Stein e JeanPierre Yvaral, e bastante ativo na França nos anos 1960. quentes e se tornara amigo de vários membros do grupo. Ao deixar o país, ocupava lugar de destaque no meio vanguardista brasileiro, e não somente como artista. "Esquema geral da Nova Objetividade", texto-manifesto que escreve para a exposição "Nova objetividade brasileira”, de 1967, é considerado contribuição "seminal para a arte contemporânea, e não apenas a brasileira" ${ }^{53}$. Portanto, faz-se evidente que, diferentemente de muitos outros artistas sul-americanos que partiram para a Europa em busca de formação, Oiticica desembarca em Londres disposto a colocar em prática um sólido programa de trabalho (e não apenas um projeto expográfico) que vinha sendo gestado há alguns anos e que também fora influenciado por suas vivências no Morro da Mangueira, no Rio de Janeiro, e por sua participação em manifestações coletivas recentes, como Apocalipopótese, de 1968. Buscava maior reconhecimento para seu trabalho e para suas ideias, mas confiava que deixaria sua marca na história da arte ocidental. Contudo, não se deve negligenciar a importância da mostra aqui tratada para o artista. Como ele próprio escreveu, "a experiência da Whitechapel confirmou-me muita coisa, derrubou outras, e me conduz à meta do que pensar e de para onde ir" ${ }^{54}$.

Para Celso Favaretto, a mostra londrina foi "um marco no programa de Oiticica: permitiu-lhe reavaliar o percurso experimental, revitalizar Núcleos e Penetráveis e experimentar as proposições do Suprassensorial em condições que não eram possíveis no Brasil” "55 . A propósito, em carta a Mário Pedrosa, Oiticica confessaria que "somente em Londres eu poderia ter conseguido colocar essa experiência-exposição em prática e realizar tantas coisas" ${ }^{56}$. Deve-se lembrar que o Brasil vivia então um período de forte repressão política e que muitos da geração - e da convivência - de Oiticica foram forçados a deixar o país naqueles anos ou sofreram as consequências do agravamento da tensão social.

É em "Whitechapel experiment" que Oiticica dá forma e concretiza seu conceito de Crelazer, sobre o qual ele escreveria recorrentemente e que impactou suas ações posteriores. Diferentemente de outras propostas artísticas interativas então em voga, que se serviam de recursos óticos e cinéticos com o objetivo de promover a participação do espectador, seja inserindo-o em ambientes com diferentes estímulos (em especial jogos de luz), seja convidando-o a manipular objetos que modificavam sua percepção visual ${ }^{57}$, Crelazer tem como propósito não apenas retirar a arte do campo do espetáculo e do consumo, mas também possibilitar um novo modo de "estar no mundo", em que o repouso se torna "alimento criativo, numa volta à fantasia profunda, ao sonho, 
ao sono-lazer, ou ao lazer-fazer não interessado" ${ }^{28}$. Tratar-se-á doravante, para Oiticica, de investir não mais na realização de obras de arte isoladas, mas no lazer não repressivo, não representativo, criativo, "que não se deixa aprisionar por valores burgueses, não se submete à mera diversão, mas busca liberar as aspirações humanas da alienação de um mundo opressivo" ${ }^{\text {59 }}$.

Conforme afirma Paula Braga, Éden tem como proposta a suspensão do curso das coisas banais:

dentro do Bólide cama de juta ou na tenda preta Caetano-Gil, que integram o Éden, o tempo é depurado. Deitado dentro da cama-bólide, o que se percebe não é a imagem, e sim a duração de cada um. Não é preciso percorrer o espaço expositivo, não é preciso chegar a nenhum fim, simplesmente estar em contato com a própria duração. ${ }^{60}$

Nesse espaço de abrigo e absorção, "aberto a vivências, à produção de novos significados" 1 , o participador constrói "seu mundo, com os elementos da sua subjetividade”, a partir das sensações despertadas pela obra. O artista é aquele "que propõe estruturas abertas diretamente ao comportamento"62. "Eu tinha algumas ideias que eu achava que eram muito abstratas, mas de repente elas se tornaram reais", escreve Oiticica para Brett quando elaborava seu projeto Éden. "A criatividade é inerente a todos, o artista deve apenas inflamá-la, atear fogo, libertar as pessoas do seu condicionamento - o velho modo de olhar para o artista como alguém inatingível está morto”63.

O conteúdo político-social, de cunho coletivo, de suas proposições se faz evidente. Nesse contexto, as sensações, assinala Tania Rivera ao discutir o trabalho de Oiticica,

não tem valor em si, como percepção, mas são estopins para alguma ação do sujeito sobre ele mesmo. O sujeito, em sua singularidade, é reafirmado e buscado, mas não no âmbito do puramente individual. Seu aparecimento é profundamente coletivo e tem impacto social, realizando uma junção entre social, psicológico e ético. ${ }^{64}$

Celso Favaretto vai além, ao afirmar que o programa de Oiticica deve ser compreendido como uma "prática revolucionária":

O que era visado era a transformação da arte em outra coisa, um além-da-arte ainda indeterminada - uma proposta em desenvolvimento em toda parte e que, de qualquer maneira, implicava mudanças nas referências à
Maria de Fátima Morethy Couto

"The Whitechapel experiment", o projeto Éden e a busca por

uma experiência afetiva total.

58. OITICICA, Hélio. A obra, seu caráter objetal, o comportamento. In: Op. cit., p. 120-121.

59. RIVERA, Tania. 0 reviramento do sujeito e da cultura em Hélio Oticica. Arte \& Ensaios, Rio de Janeiro, v. 16, n. 19, 2009, p. 114.

60. BRAGA, Paula. Hélio Oiticica: singularidade, multiplicidade. São Paulo: Perspectiva, 2013, p. 176.

61. FAVARETTO, Celso. Op. cit., p. 189.

62. OITICICA, Hélio. A obra, seu caráter objetal, o comportamento. In: Op. cit., p. 120.

63. Carta de Oiticica para Guy Brett, de 2 de abril de 1968. In: WHITECHAPEL ART GALLERY. Whitechapel Gallery archive. Londres, 2009, WAG/EXH 2/122. Tradução minha.

64. RIVERA, Tânia. 0 reviramento do sujeito e da cultura em Hélio Oiticica. Arte \& Ensaios, Rio de Janeiro, v. 16, n. 19, 2009, p. 114. 
65. FAVARETTO, Celso

Deslocamentos: entre a arte e a vida. Ars, São Paulo, v. 9, n. 18, 2011, p. 100-101. Em entrevista concedida a Gilse Campos, na ocasião de seu primeiro retorno ao Brasil, em janeiro de 1970 , Oiticica declara: "Para mim, a participação do espectador e introdução de elementos sensoriais foram importantes para a introdução de uma nova forma de comportamento lque é muito mais dirigido à vida diária), e não a criar uma nova forma de arte. Isso para mim não interessa, acaba virando objeto". Cf. CAMPOS Gilse. Uma arte sem medo. In: OITICICA FILHO, César; COHN, Sergio; VIEIRA, Ingrid (orgs.). Op. cit., p. 89-90. Artigo publicado originalmente no Jornal do Brasil, em 29 de janeiro de 1970

66. Nesse mesmo período, Lygia Clark articulava na França a organização de um dossiê sobre Oiticica na revista de vanguarda Robho, editada pelo crítico Jean Clay e pelo poeta Julien Blaine. Oiticica

inclusive enviou vários de seus textos para Clay e aguardava ansiosamente pela publicação, que acabou não ocorrendo.

Todavia, em 1971, Robho publica um dossiê dedicado ao corpo e à unidade do campo perceptivo (Unité du champ perceptif: interaction des corps: architectures vivantes: pivots humais: pratique tribale), no qual o trabalho de Oiticica é comentado, sem maiores destaques, juntamente com a obra de diversos outros artistas, de diferentes nacionalidades. vida em projetos diversos de renovação da sensibilidade contemporânea que explora a provisoriedade do estético e ressignifica a criação coletiva e o político da arte. A tendência básica do programa de Oiticica era a transformação da arte em outra coisa; em "exercícios para um comportamento" operados pela participação". ${ }^{65}$

Logo após sua experiência na Whitechapel, Oiticica escreve o texto "The senses pointing towards a new transformation", para apresentação no simpósio First International Tactile Sculpture Symposium, que mencionarei novamente adiante. Seu interesse em divulgar suas ideias do modo mais amplo possível leva-o a enviar esse texto para a revista Studio International, com vistas a uma publicação que nunca ocorreu $^{66}$. Nele, Oiticica revela-se seguro de não poder continuar suas experiências Crelazer em espaços de museus e galerias ${ }^{67}$. Cabe lembrar que Oiticica já havia abordado o tema em texto de 1968, no qual relacionava seu conceito de "recinto-proposição" às experiências primeiras de Mondrian e Schwitters em torno da "casa-obra" e declarava que "a insuficiência das estruturas de museus e galerias de arte, por mais avançados que sejam, é hoje em dia flagrante e trai, em muitos casos, o sentido profundo, a intenção renovadora do artista. (...) Já se vê que a velha sala de museu, eclética, dando para outra onde se exibe outra "obra completa" etc., não dá mais pé”68.

Em maio de 1969, logo após o encerramento da mostra na Whitechapel, Oiticica visita Lygia Clark em Paris, onde ela residia desde setembro de 1968, mas não se interessa pelo circuito parisiense, comentando em carta à amiga que "se sentiu bem infeliz em Paris, não viu grandeza em nada" ${ }^{69}$. Nesta mesma carta, Oiticica critica o clima de desconfiança e competição pueril que encontrou na França, inclusive da parte de Clark, desdenhando ainda a relação conflituosa existente entre outros artistas sul-americanos e se colocando avesso a esse tipo de disputa por mercado:

esse negócio de sempre comparar meu trabalho com o seu, tentando diminuir o sentido profundo do meu, me irrita e na realidade não existe: no meu trabalho posso estabelecer relações a posteriori ou não com o seu, mas nada devo a ele, nada devo a ninguém - sei o que faço e penso, por isso há anos escrevo [sobre seu trabalho] para deixar tudo claro. (...) Essa merda de competição, da qual você me cita o caso Soto-Le Parc, penso assim: não pertence a meu mundo depois que formulei a ideia de Éden, e Crelazer: é coisa velha, do passado, pertence à classe de pensamentos corruptos, opressivos, que são a contradição do que quero com o Crelazer. ${ }^{70}$ 
A querela com Clark foi passageira, pois logo em seguida, em julho de 1969, viajam juntos para Long Beach, na Califórnia, para participar do First International Tactile Sculpture Symposium, no California State College. Ao retornar para o Reino Unido, Oiticica passa três meses em Brighton como artista residente do Gardner Arts Centre, vinculado à Sussex University, onde retoma elementos da mostra londrina $\mathrm{e}$ dá continuidade a seu programa ambiental, montando diversos tipos de Ninhos com os estudantes da universidade. Ao escrever sobre esta proposta de "núcleo-casa", que fundamentaria seu projeto Barracão (uma comunidade "enorme", orgânica, que almejava executar no Rio de Janeiro), Oiticica mencionaria sua similaridade com a "experiência total a que se entrega[va] o grupo Exploding Galaxy de Londres":

A casa onde, vivem, que pode não ser só aquela mas será a que houver onde quer que andem, tem esse caráter de um ambiente-recintotal - até a comida, o comer, o vestir, o ambiente em si, mostram que lá com eles a vida e a obra não se podem separar, pois na realidade não há essa diferença mesmo. ${ }^{71}$

Como observou Brett, Oiticica "demonstrou muito pouco interesse pelo mundo mainstream da arte britânica. Para ele, as façanhas do Exploding Galaxy apresentavam uma perspectiva mais excitante do que a New British Sculpture. Ele ficou fascinado pela metrópole de Londres e fez muitos amigos aqui, mas sua mente estava constantemente no Brasil, em particular no Rio de Janeiro" 72 . Contudo, na opinião de Michael Asbury,

O impacto de Londres em Oiticica foi profundo. Ele conferiu uma dimensão internacional à sua crença em práticas não institucionais, mas talvez ainda mais importante, ele o fez redirecionar sua tentativa de dar forma a um caráter mítico brasileiro. Além disso, Oiticica experimentou um sentimento ambivalente de identidade, em Londres. Apesar de totalmente envolvido com dinâmicas culturais brasileiras, ele sofreu a consequência comum da migração, a perda de pertencimento. ${ }^{73}$

Ao comentar sobre sua estadia em Londres e em Brighton em texto escrito já no Brasil, Oiticica destaca a importância de suas relações com o Exploding Galaxy, relações essas que, a seu ver, "não eram acidentais: houve sempre uma ligação espiritual e uma finalidade mútua". Afirma, ademais, que lá chegara "ao limite de tudo: a necessidade de desenvolver cada vez mais algo que fosse extra-exposição, extra-obra, mais do que o objeto participante, um contexto para o comportamento,
130

Maria de Fátima Morethy Couto

"The Whitechapel experiment", o projeto Éden e a busca por uma experiência afetiva total.

67. Para Paula Braga, trata-se de texto fundamental para a compreensão do pensamento e das proposições de Oiticica dos anos seguintes. Cf. BRAGA, Paula. Op. cit., p. 169-179.

68. OITICICA, Hélio. A obra, seu caráter objetal, o comportamento. In:

Op. cit., p. 119.

69. Carta de Hélio Oiticica para Lygia Clark, de 7 de junho de 1969. In: FIGUEIREDO,

Luciano (org.). Op. cit., p. 104.

70. Ibidem. p. 102. (Grifos do artista). Nesta mesma carta, afirma ainda que "a ideia de objeto-arte vendável é coisa do passado - objeto-arte não existe hoje para mim, escrevi muito sobre isso e é uma posição real a que devo ser fiel; quero um novo comportamento, integral, que exclua toda sorte de ideia corrupta, pequenês do mundo de arte, classe social (diferenças), intolerância com pessoas nas relações etc". Cf. Ibidem, p. 102-103.

71. OITICICA, Hélio. A obra, seu caráter objetal, o comportamento. In:

Op. cit., p. 121.

72. BRETT, Guy. Recollection. In: BRETT, Guy; FIGUEIREDO, Luciano (orgs.). Op. cit., p. 14 e 16.

73. ASBURY, Michael. This other Eden: Hélio Oicica and subterranean London. In: BRETT, Guy; FIGUEIREDO, Luciano (orgs.). Op. cit., p. 38. 
para a vida”. E continua, enfatizando uma vez mais, o quanto as expe-

ano 15

n. 30

74. OITICICA, Hélio.

Experiência londrina: subterrânea, 27 jan. 1970. In: ITAÚ CULTURAL. Programa Hélio Oiticica. São Paulo, 2002, AHO/PHO 0290/70, p. 1-2.

75. Carta de Hélio Oiticica para Lygia Clark, de 23 de dezembro de 1969. In: FIGUEIREDO, Luciano (org.). Op. cit., p. 128

76. Para Paula Braga, em "Information" Oiticica usa o museu não como lugar de acontecimento da obra, mas como lugar de propagandear

informes sobre a obra. Ao instalar seus Ninhos no

MoMA, Oiticica "usa o museu como vitrine, para tornar seu trabalho conhecido em Nova York", afirma a autora. In: BRAGA, Paula. Op. cit., p. 192-193. Segundo Amanda Ruggiero, foi devido à visibilidade da "The Whitechapel experience", Hélio Oiticica foi convidado para participar da exposição "Information". RUGGIERO, Amanda. Op. cit. p. 189

Artigo recebido em 20 de julho de 2017 e aceito em 4 de setembro de 2017 riências ali vividas apontaram-lhe novos caminhos: "à minha atividade atual no seu todo, quero chamar de 'subterrânea': não será exposta, mais feita, seu lugar no tempo é aberta"74.

Oiticica retorna da Inglaterra ao Brasil em janeiro de 1970 e concede algumas entrevistas sobre seu trabalho (aqui parcialmente citadas), nas quais comenta sua passagem pela Europa e fala sobre seus projetos futuros. Todavia, não quer "aparecer nem fazer coisas públicas, pois seria uma compactuação com o regime"75. Logo em seguida, apesar de suas recorrentes críticas ao sistema de arte e às instituições artísticas, aceita o convite feito por Kynaston Macshine para participar de "Information", mostra realizada entre julho e setembro de 1970 no Museu de Arte Moderna (MoMA) de Nova Iorque e que se tornará um marco na história das exposições de cunho experimental ${ }^{76}$.

Oiticica residirá por oito anos em Nova Iorque, a princípio subsidiado por uma bolsa da Fundação Guggenheim. Lá dará sequência às experiências Crelazer, elaborando projetos diversos e fundando o que Paula Braga considera a grande questão do artista nos anos 1970: o "além-participação". Em Nova Iorque, seu trabalho transbordará de vez para fora dos limites estreitos das instituições artísticas, voltando-se para o espaço de convívio público, seja a rua, seja o espaço privado compartilhado. Seu apartamento é por ele transformado em um espaço feito de muitos Ninhos (Babylonests), nos quais vivia, trabalhava e recebia seus amigos, certo de com isso estabelecer um cotidiano criativo, um lazer insubmisso, que assumia a instabilidade e a precariedade como um convite a descobertas e mutações constantes.
Maria de Fátima Morethy Couto é professora livre-docente do Instituto de Artes da Universidade Estadual de Campinas [Unicamp] e pesquisadora do Conselho Nacional de Desenvolvimento Científico e Tecnológico [CNPq]. Autora do livro Por uma vanguarda nacional. A crítica brasileira em busca de uma identidade artística - 1940/1960 [Ed. Unicamp, 2004] e coautora/organizadora dos livros ABCdaire Cézanne [Flammarion, 1995], Instituições da Arte [Zouk, 2012], Espaços da arte contemporânea [Alameda, 2013], História das artes em exposições: modos de ver e de exibir no Brasil e Histórias da arte em coleções [Riobooks, 2016]. 
